\title{
Clickers 201: Exploring the Next Levels of Using Classroom Response Systems in Science Courses
}

\author{
Tanya Noel \\ York University
}

While there is a wealth of information and resources for new users of classroom response systems, much is yet to be explored, particularly for experienced instructors hoping to leverage this technology further in support of effective learning. In this paper, I highlight recent literature findings, and suggest some areas for future exploration and discussion.

\section{Introduction}

Classroom response systems (CRS) or "clickUers" are remote-control type devices students use to answer questions posed by the instructor; a computer, receiver, and software capture responses. With these systems, instructors can transform large, impersonal lecture halls into dynamic environments for active learning, instant feedback, and discussion. CRS allow instructors to bridge the physical environment and the virtual, allowing real-time contributions from all students, and providing opportunities for immediate feedback.

Despite initial skepticism among science educators, CRS are gaining more acceptance as tools to support learning. In fact, until five years ago, I was doubtful that the addition of yet another technology to my classroom would be beneficial. However, having read some compelling reports (Beatty, 2004; Wood, 2004), I carried out a pilot study in a large (> 90 stu- dent) microbiology course. Like many adopters, I was struck by the change in classroom dynamic, and student feedback was very positive. I wasn't alone; my observations mirrored what other implementers were reporting (e.g., Crossgrove \& Curran, 2008; Preszler, Dawe, Shuster, \& Shuster, 2007).

In the past few years, I have attended several (and delivered some) of the many workshops/ seminars aimed at individuals considering use of CRS. There have been a wealth of such introductory (“Clicker 101") sessions offered at various educational conferences, as well as teaching and learning support centres at universities. Similarly, there is a growing body of resources for individuals seeking general guidelines (see the CWSEI/CU-SEI, Clicker Resource Guide, 2009; Duncan, 2005), and best practices (e.g., Caldwell, 2007); reports recounting individual experiences in different science classes abound. However, 
there are fewer resources available for experienced CRS users seeking to extend use of this technology. In this paper, I have highlighted some of the resources available in science education literature, as well as directions for further exploration.

\section{What Do We Know?}

Many potentially helpful anecdotal reports are available for instructors preparing to use clickers in the science classroom, and want to know what to expect. The value of using CRS to foster improvement in student performance is also something many instructors wonder about. A number of papers indicate benefits in terms of improved attendance and engagement (see Crossgrove \& Curran, 2008; Gauci, Dantas, Williams, \& Kemm, 2009; Preszler et al., 2007). Unsurprisingly, given the difficulties inherent with implementing comparative studies, there is less evidence showing clear benefit in learning outcomes. (Indeed, there is considerable discussion among educators in terms of how to best measure that learning has occurred!) Comparative studies can prove challenging in terms of ethically including appropriate controls, and controlling variables. Among comprehensive studies of CRS, some have demonstrated significant improvement in learning outcomes (Freeman et al., 2007; Mayer et al., 2009). These studies, and others (Morling, McAuliffe, Cohen, \& DiLorenzo, 2008), have demonstrated increases in student grades with clicker use.

While Morling et al. (2008) has been cited (e.g., Campbell \& Mayer, 2008; Morgan, 2008) as an example of increased grades in association with CRS use, the study reports that clicker use in the study group was rare/minimal. In fact, the authors note that they deliberately avoided using clickers with known pedagogical strategies, and specifically mention that future studies could investigate the incorporation of CRS with such strategies. Viewing CRS as a tool, akin to a computer, presentation software, or learning management system, I find it difficult to envision how clickers could affect student learning in a meaningful way without being used with established teaching methods. Indeed, other educators indicate CRS are tools best used in support of known strategies that facilitate student learning, such as peer teaching (Mazur, 1997). Beatty and Gerace (2009) state: "don't ask what the learning gain from CRS use is; ask what pedagogical approaches a CRS can aid or enable or magnify, and what the learning impacts of those various approaches are" (p. 147).

Some studies do clearly indicate pedagogical approaches that can be used with clickers. For example, CRS are well suited to support question-driven activities, known to support high-quality learning. Beatty, Gerace, Leonar, and Dufresne (2006) provide guidelines in setting goals for questions - each question should have a clear pedagogic purpose for content, process, and metacognition. While their examples are rooted in physics, I find the guidelines extremely helpful in constructing biology questions. Examples of CRS questions, as well as practical suggestions, are also available from other sources (e.g. Duncan, 2005).

Dangel and Wang (2008) discuss the use of CRS in supporting effective teaching practices and promoting deep (vs. surface) learning. They note that clickers are commonly used to support only a few of the "principles for good practice" in teaching described by Chickering and Gamson (1987), such as an emphasis on time-on-task, prompt feedback, and facilitating student-instructor contact. Similarly, CRS were primarily used to target lower cognitive levels (per Anderson \& Krathwohl, 2001, revised from Bloom, 1956). In some cases, CRS were reported as supporting other principles of good practice (i.e., to develop student cooperation and active learning, and to communicate high expectations). It appears possible to use clickers to support all the principles for good practice, and address higher-order cognitive skills.

It is apparent that an instructor seeking a magic bullet to improve student performance is likely to be disappointed. There is evidence that CRS support good teaching/learning approaches, but as with any tool, benefits can be expected only when the system is used thoughtfully and aligned with the pedagogical strategy chosen by the instructor. 


\section{Where Are We Going?}

From my own experience, what has been reported in the literature, and discussions with other instructors, there are several areas where further study/communication would be beneficial. I've described some below, but this is not an exhaustive list - many avenues for exploration and future studies exist!

\section{Question construction, use, sharing}

Beatty et al. (2006) and others (Nicol 2007; Palmer $\&$ Devitt 2007) have provided guidelines for the development of multiple-choice questions that promote effective, higher-order learning. Referencing Bloom's Taxonomy, a significant number of multiple-choice questions in the Medical College Admission Test (MCAT) assess higher-order thinking skills (Zheng, Lawhorn, Lumley, \& Freeman 2008). This supports the observation by Dangel and Wang (2008), suggesting that there is potential for increased use of CRS to foster higher-order thinking skills.

Although students enjoy in-class demonstrations, Crouch, Fagen, Callan, and Mazur (2004) have shown that meaningful learning does not typically occur just by viewing such demonstrations. However, if students are asked to predict the outcome of the demonstration, learning increases; clickers can be used to poll student predictions ahead of a demonstration, and used in an instructor-defined framework for post-demonstration reflection and discussions. Shared examples of useful experiments that have accompanying annotations to help instructors to use such activities in classes would likely be well received in most scientific disciplines.

Specific guidelines for using/developing clicker questions in support of peer instruction, case studies, and problem-based-learning activities would be welcomed, particularly for instructors of large classes who may be daunted by the idea of facilitating these activities without supporting technology.

Currently, some publishers make questions available to adopters of certain textbooks, but quality of such question banks is variable. (Test banks for multiple-choice exams exist, but also vary in quality, and not all of these questions are best used as in-class clicker questions.) Tested, annotated banks of clicker questions for various scientific disciplines and topics would be welcomed.

\section{Quality of learning, metacognition}

CRS may prove valuable in metacognitive exercises, helping students develop awareness of their own learning. Crowe, Dirks, and Wenderoth (2008) describe successful attempts to bring such metacognition into the classroom. These authors developed an assessment tool, which both students and faculty could use to evaluate biology questions according to Bloom's Taxonomy levels. Students examine what questions are asking for: knowledge, comprehension, application, etc. Improvements in student study skills and metacognition were observed when students were trained in, and used, the assessment tool. Wider use of this tool, or other metacognitive exercises tied to clicker questions could promote higher quality learning.

The SOLO Taxonomy is another framework for evaluating the quality of learning and progression towards mastery of a discipline (Biggs \& Collis, 1982). Students can be encouraged to move towards deeper learning and develop associated study practices (Biggs, 2001). I believe that we have an opportunity to encourage students to assess their own levels of mastery and awareness of study practices via CRS, similar to the "Blooming Biology" tool described by Crowe et al. (2008). (Annotating clicker questions with the Bloom's Taxonomy and/or SOLO Taxonomy levels targeted would be useful for instructors using discipline-specific question banks.)

\section{Concept inventories}

Concept inventories are collections of multiplechoice questions designed to determine students' conceptual understanding in a particular field. Questions deal with core concepts and distractors reflect common student misconceptions. The Force Concept Inventory's (Hestenes, Wells, \& Swackhamer, 1992) success in provoking reform in physics education has prompted development of other concept inventories. The relationship between CRS and concept inventories is two-fold. Questions from concept 
inventories delivered through CRS could be helpful for instructors to monitor student conceptual learning in class. CRS can also be used to help identify troublesome concepts and common misconceptions, which could then be used in the development, or refinement, of concept inventories. (Item analyses will highlight good vs. poor distractors.)

\section{Emerging uses of clickers...and potential issues}

Several intriguing aspects of advanced CRS use have been suggested, but are not well-studied:

1. CRS could be used to identify at-risk students, simply based upon late clicker registration (not simply attendance, nor poor scores on clicker questions), allowing instructor intervention at relatively early stages in a course (Griff \& Matter, 2008). Other strategies for identification of at-risk students are possible, based on student responses/scores, but we await further studies on such methods to speculate on the best strategy.

2. Can CRS affect student retention? The shift in classroom activities and atmosphere due to CRS use could counter some of the traditional issues students perceive with science courses, leading to attrition (Seymour \& Hewitt 1997; Tobias 1990). Caldwell (2007) reports a decrease in attrition during a course, but it would be interesting to know if CRS may contribute to retention in the longer term.

3. Use of clickers in class could provide opportunities for students with disabilities to comfortably participate in discussion activities, as peer anonymity may encourage more authentic sharing (N. Israelite, personal communication, 2007). There is also a need to explore potential issues faced by students with disabilities; strategies and possible accommodations should be developed and disseminated so that all students can benefit from the pedagogical strategies supported by CRS.

4. CRS allow data collection in ways that had not been easily possible in a classroom setting until recently. Reports can be generated for various purposes (e.g., student scores, question item analysis). Software varies between different vendors of CRS, so accessing and compiling these data differ by product. Some standardization of data files/reports and clear guidelines for analysis of CRS data could allow individual instructors to leverage collected data in many ways (e.g., improving clicker questions, tracking trends across different academic sessions, etc.) and provide opportunities for aggregation of data beyond the individual course/instructor.

5. A concern highlighted by the participants of the Clickers 201 STLHE 2009 session relates to privacy and ethics of CRS use. As mentioned, rapid and copious data collection is possible, and instructors can link responses to individual students (unless "anonymous" mode is selected in the software, or students exchange clickers temporarily). Public awareness of privacy rights, along with increasing use of CRS, may necessitate clear guidelines regarding data collection and privacy.

\section{Conclusion}

It is an exciting time to be using classroom response systems in undergraduate science education. While a body of literature and many introductory resources exist for new users of CRS, additional information and support for experienced CRS users would be enthusiastically welcomed. The nature of CRS as a tool to support effective pedagogical strategies (as opposed to use of clickers just to bring another technology into the room) has not been widely disseminated, yet is important in understanding key benefits and limitations of the technology. Some potential areas for further exploration include sharing of fieldtested clicker question banks, integration of SOLO taxonomy levels in question design/implementation, and the use of CRS in development of concept inventories. As we move forward with this technology, however, we must keep in mind that considerations surrounding accessibility, privacy, and data collec- 
tion through CRS use have yet to be fully explored. I, like many others, am optimistic that a community of educators using CRS can develop and share information that will serve to improve the use of clickers in science teaching.

\section{Acknowledgements}

Thanks go to Tamara Kelly, Logan Donaldson, and the reviewers for helpful comments and suggestions.

\section{References}

Anderson, L.W., \& Krathwohl, D.R. (2001). A taxonomy for learning, teaching and assessing: $A$ revision of Bloom's Taxonomy of educational objectives. New York: Longman.

Beatty, I. (2004). Transforming student learning with classroom communication systems. EDUCAUSE Center for Applied Research: Research Bulletin, 2004(3), 1-13. Retrieved from http://www.educause.edu/ir/library/pdf/ ERB0403.pdf

Beatty, I.D., Gerace, W.J., Leonar, W.J., \& Dufresne, R.J. (2006). Designing effective questions for classroom response system teaching. American Journal of Physics, 74(1), 31-39.

Beatty, I.D. \& Gerace, W.J. (2009). Technologyenhanced formative assessment: A researchbased pedagogy for teaching science with classroom response technology. Journal of Science Education and Technology. 18, 146152.

Biggs, J.B. (2001). The revised two-factor Study Process Questionnaire: R-SPQ-2F, British Journal of Educational Psychology, 71, 133-149.

Biggs, J. \& Collis, K. (1982). Evaluating the quality of learning: The SOLO taxonomy. New York: Academic Press.

Bloom, B.S. (1956). Taxonomy of educational objec- tives: The classification of educational goals. New York: Longman, Green.

Caldwell, J.E. (2007). Clickers in the large classroom: Current research and best-practice tips. $C B E$ Life Science Education, 6, 9-20.

Campbell, J. \& Mayer, R.E. (2008). Questioning as an instructional method: Does it affect learning from lectures. Applied Cognitive Psychology, 23, 747-759.

Carl Wieman Science Education Initiative, University of British Columbia, and the Science Education Initiative, University of Colorado. [CWSEI/CU-SEI]. (2009). Clicker resource guide. Retrieved from http://www.cwsei.ubc. $\mathrm{ca} /$ resources/files/Clicker_guide_CWSEI_ CU-SEI.pdf

Chickering, A.W. \& Gamson, Z.F. (1987). Seven principles for good practice in undergraduate education. AAHE Bulletin, 39(7), 3-7.

Crossgrove, K. \& Curran, K.L. (2008). Using clickers in nonmajors- and majors-level biology courses: Student opinion, learning, and longterm retention of course material. CBE Life Science Education, 7, 146-154.

Crouch, C.H., Fagen, A.P., Callan, J.P. \& Mazur, E. (2004). Classroom demonstrations: Learning tools or entertainment? American Journal of Physics, 72, 835-838.

Crowe, A., Dirks, C., \& Wenderoth, M.P. (2008). Biology in Bloom: Implementing Bloom's Taxonomy to enhance student learning in biology. CBE Life Science Education, 7, 368381.

Dangel, H.L. \& Wang, C.X. (2008). Student response systems in higher education: Moving beyond linear teaching and surface learning. Journal of Educational Technology Development and Exchange, 1(1), 93-104. 
Duncan, D. (2005). Clickers in the classroom: How to enhance science teaching using classroom response systems. San Francisco: Pearson Education.

Freeman, S., O’Connor, E., Parks, J.W., Cunningham, M., Hurley, D., Haak, D., et al. (2007). Prescribed active learning increases performance in introductory biology. CBE Life Science Education, 6, 132-139.

Gauci, S.A., Dantas, A.M., Williams, D.A., \& Kemm, R.E. (2009). Promoting studentcentered active learning in lectures with a personal response system. Advanced Physiological Education, 33, 60-71.

Griff E.R., \& Matter, S.F. (2008). Early identification of at-risk students using a personal response system. British Journal of Educational Technology, 39, 1124-1130.

Hestenes, D., Wells, M., \& Swackhamer, G. (1992). Force concept inventory. The Physics Teacher, 30, 141-151.

Mayer, R.A., Stull, A., DeLeeuw, K., Almeroth, K., Bimber, B., Chun, D., et al. (2009). Clickers in college classrooms: Fostering learning with questioning methods in large lecture classes. Contemporary Educational Psychology, 34, 5157.

Mazur, E. (1997). Peer instruction: A user's manual. Upper Saddle River: Prentice Hall.

Morgan, R.K. (2008). Exploring the pedagogical effectiveness of clickers. InSight: A Journal of Scholarly Teaching, 3, 31-36.

Morling, B., McAuliffe, M., Cohen, L., \& DiLorenzo, T.M. (2008). Efficacy of personal response systems (clickers) in large, introductory psychology classes. Teaching of Psychology, 35, 45-50.
Nicol, D. (2007). E-Assessment by design: Using multiple-choice tests to good effect. Journal of Further and Higher Education 31, 53-64.

Palmer, E.J. \& Devitt, P.G. (2007). Assessment of higher order cognitive skills in undergraduate education: Modified essay or multiple choice questions? BMC Medical Education, 7, 49.

Preszler, R.W., Dawe, A., Shuster, C.B., \& Shuster, M. (2007). Assessment of the effects of student response systems on student learning and attitudes over a broad range of biology courses. CBE Life Science Education, 6, 2941.

Seymour, E. \& Hewitt, N.M. (1997). Talking about leaving: Why undergraduates leave the sciences. Boulder: Westview Press.

Tobias, S. (1990). They're not dumb, they're different: Stalking the second tier. Tuscon: Research Corporation.

Wood, W.B. (2004). Clickers: A teaching gimmick that works. Developmental Cell, 7, 796-798.

Zheng, A.Y., Lawhorn, J.K., Lumley, T., \& Freeman, S. (2008). Application of Bloom's Taxonomy debunks the "MCAT Myth." Science, 319, 414-415.

\section{Biography}

Tanya Noel is an Associate Lecturer in the Biology Department and a CST Scholar working with the Centre for the Support of Teaching at York University. Interests include understanding/improving quality of learning in science courses, particularly at the first-year level. 